\title{
MANIFESTAÇÕES BUCAIS DA DOENÇA ENXERTO CONTRA HOSPEDEIRO EM PACIENTES TRANSPLANTADOS DE MEDULA ÓSSEA.
}

Rafaela Elvira ROZZA, Roberta NOVAES, José Miguel AMENÁBAR, Roberta STRAMANDINOLI, Cassius Carvalho TORRES-PEREIRA

A doença enxerto contra hospedeiro (DECH) é uma síndrome que acomete pacientes pós-transplante alogênico de medula óssea (TMO). Esta desordem envolve uma reação imunológica entre as células linfóides do doador e tecidos do hospedeiro, as quais diferem daquelas pelos antígenos de histocompatibilidade. O objetivo deste trabalho é auxiliar o profissional a tratar a $\mathrm{DECH}$ de acordo com o seu diagnóstico definitivo, auxiliando na escolha das melhores medidas de tratamento desta desordem. Histologicamente apresenta degeneração de células epiteliais e presença de infiltrado inflamatório monocelular, principalmente células $\mathrm{CD}^{+}$e macrófagos, em locais como pele, fígado, trato gastrointestinal, pulmões, boca, glândulas salivares e olhos. Dentre as alterações bucais, as mais comuns são reações liquenóides, placas hiperceratóticas, eritema, xerostomia e língua despapilada. As manifestações da DECH podem ocorrer nos primeiros três anos pós-TMO (forma aguda), após 100 dias (forma crônica) ou ambas simultaneamente. O diagnóstico definitivo é confirmado por exame histológico da lesão, testes laboratoriais e de imagem dos órgãos afetados. As estratégias preventivas e o tratamento da DECH geralmente baseiam-se na terapia profilática, com o uso de imunossupressores como ciclosporina e corticóides. O estomatologista tem papel importante na avaliação clínica, auxiliando no reconhecimento precoce, complicações e acompanhamento de pacientes transplantados. 